\title{
A Trilha Interpretativa da Vila do Americano - PA, Brasil: uma busca por conservação ambiental
}

The Interpretative Trail of Americano Village - PA, Brazil: a quest for environmental conservation

\author{
Angelo Mariano Nunes Campos ${ }^{1}$ \\ Eduardo Antônio Ferreira ${ }^{2}$
}

\begin{abstract}
RESUMO: O presente trabalho mostra o ecoturismo como atividade que busca proporcionar o desenvolvimento para a comunidade da Vila do Americano. Propõe conciliar a relação de preservação versus desenvolvimento por meio de uma trilha interpretativa, no caso específico a Trilha do Americano, que visa contribuir com a sustentabilidade dessa comunidade. Para o desenvolvimento desta pesquisa foi usada a metodologia qualitativa, com entrevista de cem visitantes. Os resultados forneceram dados interessantes, como a mudança do comportamento dos visitantes da trilha em relação à preservação do meio ambiente e o aumento do conhecimento da comunidade local sobre ecoturismo e conservação ambiental, contribuindo assim com a sensibilidade da comunidade local.
\end{abstract}

PALAVRAS-CHAVE: ecoturismo; trilha interpretativa; meio ambiente; ecossistema tropical.

ABSTRACT: The present study shows the ecotourism as an activity that searchs to provide the development for the community of the Americano Village; proposes to reconcile the relation of preservation versus development through an interpretative trail, in the specific case the Trail of the Americano Village, what aims to contribute with the sustenaible development of this community. For the development of this research, the qualitative methodology was used,

1. Bacharel em Turismo pela Universidade Federal do Pará - UFPA; especialista em Docência e Metodologia de Pesquisa em Turismo pela UFPA; professor do Curso de Turismo e Hospitalidade do CEFET-PA e da Faculdade de Belém - FABEL.E-mail: angcampos@yahoo.com.br.

2. Bacharel em Turismo pela Universidade Federal do Pará - UFPA; especialista em Docência e Metodologia de Pesquisa em Turismo pela UFPA. E-mail: duferreira@uol.com.br. 
with interview of a hundred visitants. It was possible to get excellent resulted on the research, such as, the change of the visitors behavior of the track in relation to the environment preservation and the increase of the knowledge of the local community on ecotourism and ambient conservation.

KEYWORDS: ecotourism; interpretative trail; environment; tropical ecosystem.

\section{Introdução}

O mundo vê hoje o ecoturismo como forma de se alcançar altos lucros. Entretanto, tal concepção gera preocupação em nossa sociedade, pois no afã de obter o lucro desejado, governos e empreendedores não se preocupam com a sustentabilidade, tanto cultural, social, ambiental e econômica do local onde se desenvolvem atividades ecoturísticas. Isso ocorre principalmente pela falta de um planejamento adequado, em que se faz necessária a participação da comunidade receptora na atuação da atividade ecoturística, causando assim o mínimo de impactos negativos para essas comunidades e também para o ecossistema local.

Para a formação de uma Trilha Interpretativa, também é preciso planejamento adequado, isto é, plano de interpretação fundamentado em bases teóricas e práticas, contribuindo para o melhor relacionamento entre a população local, os visitantes e os recursos naturais da região, pois por meio desse envolvimento poderá ocorrer um equilíbrio dinâmico entre os mesmos, em que tomarão conhecimento da importância dessa atividade por meio de programas de interpretação ambiental da trilha. Dessa forma, a trilha interpretativa será o meio pelo qual as pessoas poderão desfrutar da natureza de maneira planejada, segura e consciente, sendo assim um instrumento pedagógico e recreativo.

O crescimento do ecoturismo no estado do Pará provoca a necessidade de levar ao conhecimento da sociedade a importância de conservar o meio ambiente, pois as pessoas vêm se envolvendo com a questão ambiental e precisam conhecer também um pouco mais sobre a atividade ecoturística. Um exemplo desse crescimento ecoturístico está na Vila de Americano, que possui a Trilha do Americano, com recursos naturais consideráveis, mas sua comunidade e visitantes, por falta de conhecimento, tem provocado a depredação do local.

O objetivo deste artigo é inserir as pessoas envolvidas no contexto do ecoturismo dentro de uma visão de preservação ambiental da trilha interpretativa "Trilha do Americano", localizada na Vila de Americano, município de Santa Izabel do Pará (Pará). A metodologia utilizada foi a qualitativa, pois a observação dos fenômenos sociais implica a participação intensiva do pesquisador no local onde ocorre o fenômeno escolhido (Dencker, 1998: 97). Neste trabalho, usou-se levantamento bibliográfico referente a ecoturismo, trilhas interpretativas e meio ambiente. Também foi realizado o levantamento documental sobre a Fazenda Nova Sião, onde se encontra a trilha interpretativa, e também um levantamento histórico da Vila de Americano, que é distrito do município de Santa Izabel do Pará.

Na pesquisa de campo utilizou-se a técnica de entrevista estruturada, objetivando obter dos visitantes e da comunidade local a percepção da trilha interpretativa. O número de visitantes da Trilha do Americano que participou das entrevistas foi de cem, entre a comunidade local e indivíduos de outros municípios, sendo que esses resultados estão descritos no subitem "Principais resultados sobre o programa de conservação da Trilha do Americano" do tópico "A Trilha Interpretativa da Fazenda Nova Sião". O questionário da entrevista foi elaborado utilizando como referência Dencker (1998). A localização geográfica dos pontos de parada na trilha foi obtida com auxílio do GPS - Global Position System.

\section{Ecoturismo e trilhas interpretativas}

O termo "ecoturismo" teve sua origem na década de 1960, pois foi usado para "explicar o intricado relacionamento entre turistas e o meio ambiente e culturas nos quais eles interagem" (Hetzer, 1965 apud Fennell, 2002: 42). Hetzer apud Fennel (2002) identificou quatro características fundamentais a serem seguidas pelo ecoturismo: “(1) impacto ambiental mínimo; (2) impacto mínimo às culturas anfitriãs; (3) máximos benefícios econômicos para as comunidades do país anfitrião; e (4) satisfação 'recreacional' máxima para os turistas participantes". Com isso, o conceito de ecoturismo se desenvolveu, pois as sociedades passaram a se preocupar com os impactos negativos que causavam ao meio ambiente, colocando em discussão novas formas de se praticar uma forma mais responsável de turismo.

Após a publicação do Relatório de Brundtland, que teve como finalidades fazer um balanço do desenvolvimento econômico mundialmente, destacar as principais conseqüências socioambientais desse modelo de desenvolvimento e propor algumas estratégias ambientais a longo prazo, visando um desenvolvimento sustentável (CMMAD, 1991 apud Souza, 1994), o mundo tem buscado novas alternativas de enfatizar o desenvolvimento sustentável, pois tanto sua teoria quanto sua prática ainda estão em processo nas várias áreas do conhecimento. No turismo, uma das alternativas de desenvolvimento sustentável têm sido buscada pelo ecoturismo. Segundo Wearing e Neil (2001: VII-VIII), o ecoturismo surge: 
[...] Para oferecer uma opcão de desenvolvimento sustentável a países, regiões e comunidades locais, proporcionando incentivo para conservar e administrar as regiões naturais e a fauna selvagem e, em conseqüência, a crucial biodiversidade da vida. O ecoturismo pode ser uma alternativa à extração voraz de recursos florestais e minerais, além de poder gerar as divisas necessárias, trazendo receitas para administrar adequadamente as áreas de proteção.

Wearing \& Neil (2001) caracterizam o ecoturismo como sendo uma alternativa possível aos problemas causados pela falta de um desenvolvimento sustentável, porque consideram que o ecoturismo pode vir a diminuir a exploração dos recursos florestais, gerar lucro e receita para administrar as áreas de proteção e, dessa forma, efetivar o discurso do desenvolvimento sustentável.

O ecoturismo pode ser caracterizado também como sendo um meio para o aumento da compreensão dos valores ambientais, por causa da mudança de como a natureza é vista pela sociedade. Para alcançar equilíbrio entre ser humano e natureza, é preciso verificar a sustentabilidade e o fortalecimento da comunidade receptora de atuação do ecoturismo. Esses princípios básicos a serem seguidos estão profundamente relacionados às trilhas interpretativas.

Segundo Lemos (1996: 151), o ecoturismo é “[...] a rede de serviços e facilidades oferecidas para a realização do turismo em áreas com recursos turísticos naturais, sendo considerado também um modelo para o desenvolvimento sustentável da região". Mas é preciso levar em consideração vários aspectos importantes no desenvolvimento do ecoturismo, como, por exemplo, integrar o turismo ao meio ambiente mediante uma arquitetura adaptada; preservar e valorizar o patrimônio natural, histórico e cultural das comunidades nas quais a atividade seja desenvolvida; a participação das comunidades locais; e a conscientização das populações locais, empreendedores turísticos e dos turistas da necessidade de proteger o patrimônio como um todo.

Quando se desenvolve o ecoturismo em um local, este deve possuir facilidades e infra-estrutura próprias, tendo nas trilhas interpretativas da natureza importante instrumento de apoio. Assim, as trilhas interpretativas tornam-se fator importante para o ecoturismo quando, por sua utilização, percebe-se algo de valor, como a conservação da natureza, expandindo a perspectiva do visitante além da simples observação dessa natureza. Assim, o ecoturismo fica caracterizado, diferenciando-se dos outros segmentos do turismo.

Para criar um sistema de trilhas interpretativas, é preciso um conjunto de caminhos e percursos construídos com diversas funções, desde a vigilância até a atividade do turismo, objetivando a interpretação da natureza, que se torna ferramenta indispensável para a busca da conscientização dos moradores e visitantes de um local. Sendo assim, as trilhas interpretativas vêm favorecer os visitantes de uma área, pois esses seguirão as teorias e práticas ensinadas por essa atividade, dando-lhes vivência sobre como preservar a natureza. A principal função das trilhas sempre foi suprir a necessidade de deslocamento. Entretanto, ao longo do tempo houve uma mudança, ou seja, de simples meio de deslocamento, as trilhas surgem como um novo meio de contato com a natureza, passando a se chamar "trilhas de interpretação do ambiente natural", pois se tornaram algumas das melhores opções aos turistas que visitam áreas protegidas ou não, o que permite maior familiaridade com o meio ambiente. Trilhas bem construídas e devidamente mantidas protegem o ambiente dos impactos de seu uso e ainda asseguram aos visitantes maior conforto, segurança e conscientização ambiental (Pagani, 1996).

Segundo Murta e Goodey (2002: 36), trilha “[...] é uma rota, já existente ou planejada, que liga pontos de interesse em ambientes urbanos ou naturais". Os "pontos de interesse", citados por Murta e Goodey, são aqueles vistos durante o caminho, mas a orientação necessária para perçebê-los só pode ser dada pela interpretação. Assim, tudo dependerá da interpretação da trilha.

O termo "interpretação" surgiu da tradição oral nos programas educativos nos Parques Nacionais dos Estados Unidos da América, tendo sido usado por Freeman Tilden em seu livro Interpretando nosso patrimônio (Serrel, 1996). A definição de interpretação ambiental é "[...] uma atividade educacional que objetiva revelar significados e relações através da utilização de objetos originais, de experiências de primeira mão e por meio de mídia ilustrativa, em vez de simplesmente comunicar informações factuais" (Tilden, 1967 apud Murta \& Goodey, 2002: 14). A idéia central colocada por Tilden está caracterizando a utilização de formas diferenciadas para se comunicar algo, como, por exemplo, a mídia ilustrativa (placas, folhetos etc). A interpretação estimula a apreciação da natureza e promove entretenimento para residentes e visitantes dos locais interpretados.

Uma trilha interpretativa é caracterizada por vários fatores que a limitam a certos aspectos, como, por exemplo, fatores ambientais que causam ação direta na utilização de trilhas interpretativas ou ainda alguns métodos que podem definir que tipo de trilha será feito. Isso é importante para o seu funcionamento, mas antes de tudo, ela sempre possuirá estreita relação com o ecoturismo, pois além de interpretar a atividade turística, busca mudar a postura do ser humano perante a natureza, dando a ele consciência ecológica capaz de manter o equilíbrio do meio ambiente.

\section{Contextualização histórica das trilhas interpretativas}

Com o estabelecimento da prática sistemática da interpretação pelo Serviço Nacional de Parques dos Estados Unidos da América, no final da década de 1950, 
teve início o surgimento das trilhas interpretativas, pois era preciso sensibilizar o crescente número de visitantes que se dirigiam na época aos parques de Yosemite e do Grand Canyon sobre a importância da preservação daqueles santuários naturais. Na Europa, os conceitos de interpretação ambiental só vieram a ser utilizados em 1960 pelos trabalhos da National Countryside Commission, que visavam a valorização de áreas rurais, parques e reservas naturais. Em 1970, foi evidenciado o conceito das trilhas visando a recuperação e a valorização de várias áreas naturais para a população local e os visitantes.

No entanto, esse afã de promover as cidades européias e norte-americanas como destinos turísticos com base na interpretação ambiental não trouxe grandes resultados, pois em virtude da exclusão da população local do planejamento turístico, causou a falta de melhor desempenho das práticas turísticas (Murta \& Goodey, 2002).

No Brasil, só foi possível se pensar em criar um sistema de trilhas, organizado a partir da criação do Parque Nacional de Itatiaia, em 1937. Mas, após 67 anos de criação desse Parque Nacional, ainda não existe um sistema de trilhas concretizado o nem infra-estrutura adequada para o seu funcionamento. As trilhas que existem não recebem manutenção e quase todas sofrem com o problema de erosão, segurança, sinalização e escassez de mapas. A implantação de um sistema de trilhas é de extrema importância, pois será um instrumento pedagógico fundamental para se ter o conhecimento da fauna, flora, geologia, geografia, das relações ecológicas, do meio ambiente e sua proteção (Andrade, 2003).

Existem algumas técnicas para interpretar algo, como textos, dramatizações, demonstrações folclóricas e também de trilhas. As experiências britânica e norte-americana, que iniciaram esse método, demonstram que é uma maneira popular de se revelar as características naturais e culturais de um lugar, tanto para visitantes quanto para moradores, contribuindo para a educação ambiental das comunidades. Para que essas técnicas interpretativas possuam boa qualidade, as mesmas não devem: usar linguagem técnica, conduzir o visitante sem permitir que ele tenha as suas próprias sensações e percepções e apresentar informações isoladas, sem conexão com o resto do texto (Carvalho, 2002).

Existem vários formatos de trilhas, como: 1) circular, que oferece a possibilidade de se voltar para o ponto de partida, sem repetir o percurso ou cruzar com visitantes; 2) forma de oito, que são muito eficientes em áreas limitadas, pois aumentam o uso desses espaços; 3 ) linear, em que seu objetivo é conectar o caminho principal a algum destino como lagos, cavernas etc. mas apresenta as desvantagens de o caminho de volta ser igual ao de ida, e a possibilidade de cruzar com visitantes; 4) atalho, onde seu início e fim estão em diferentes pontos de uma trilha. As trilhas possuem variados graus de dificuldade, podendo ser leves, moderadas, ou pesadas, sendo que se deve levar em consideração que essa última classificação varia de pessoa para pessoa, dependendo basicamente do condicionamento físico e peso da eventual bagagem carregada, como também da extensão do percurso, características do relevo, sinalização e outros (Andrade, 2003).

Existem dois tipos de trilhas interpretativas, a guiada e a autoguiada. As trilhas guiadas são realizadas por um grupo de pessoas que requerem a presença de um intérprete ou guia. Ele acompanha os visitantes na caminhada, levando-os a observar, sentir, experimentar, refletir, questionar e descobrir os fatos relacionados ao tema estabelecido, estimulando com isso a participação do grupo, fazendo com que usem os sentidos. Existem vantagens e desvantagens nesse tipo de trilha. As vantagens são: o visitante pode obter respostas às suas dúvidas com o intérprete; há um controle mais eficaz da integridade do patrimônio; o risco de degradar o ambiente é menor; e o programa é adaptável ao usuário. Já as desvantagens são: a qualidade da mensagem depende do conhecimento do guia; o visitante é obrigado a acompanhar o ritmo do guia; os passeios têm de ser feitos com reduzido número de pessoas. Existem três tipos de trilhas guiadas: 1) natural geral, em que o intérprete percorre um caminho de um ponto de partida até outro ponto final, sem estruturar atividades fixas; 2) natural temática, em que o intérprete fixa as paradas com antecedência, dando maior coerência ao passeio; 3 ) específica, que objetiva satisfazer interesses dos visitantes, como a observação de aves (Lemos, 1996).

As trilhas autoguiadas são aquelas com pontos de parada marcados, onde o visitante, auxiliado por métodos de placas, painéis ou roteiros, que contêm informações, explora o percurso sem o acompanhamento de um intérprete ou guia. As vantagens desse tipo de trilha são: permite receber maior número de visitantes; possibilita que o visitante percorra a trilha no seu próprio ritmo e conveniência. As desvantagens são: o custo de manutenção pode ser alto; está exposto ao vandalismo; não responde às necessidades espontâneas. Em relação às trilhas autoguiadas, existem três tipos: 1) temática, que tem a finalidade de interpretar um tema coerente à trilha; 2) "miscelânea", que objetiva interpretar vários aspectos, mas sem tentar estabelecer uma relação entre eles; 3) natural, que tem a finalidade de identificar as características naturais do local por meio de placas (Lemos, 1996).

\section{Aspectos socioeconômicos da Vila do Americano}

A localização do município de Santa Izabel do Pará é na zona fisiográfica microrregião Bragantina, sendo pertencente à mesorregião Metropolitana de Belém. A Vila de Americano é um dos três distritos que compõem Santa Izabel do Pará. Os outros dois distritos são Caraparu e a sede do município. A origem do nome 
Americano remonta aos anos de 1885 a 1889, em que um cidadão norte-americano, chamado Thomas Kellmon, se destacou por ter sido proprietário de um grande engenho de cana-de-açúcar, e assim pôde ajudar doentes infectados de malária pela distribuição de quinino em pó. Com isso, sua casa tornou-se referência na região e as pessoas passaram a procurá-lo usando uma forma característica: "vou buscar remédio no americano", "te encontro no americano" e "vou pernoitar no americano". Dessa forma, o nome do distrito tornou-se popular pelos moradores da região. A principal atividade econômica é a agricultura, na qual os produtoschave são a mandioca e seus derivados, como: farinha, tapioca e tucupi (Ferreira, 1984; PARATUR, 2001).

A Trilha do Americano situa-se na Fazenda Nova Sião, localizada no distrito de Americano. Ela encontra-se à margem da antiga Estrada de Ferro de BelémBragança, no quilômetro 60, onde hoje é a rodovia BR-316. Havia uma parada do trem a cinco quilômetros da fazenda, que se chamava Parada Baia, onde hoje funciona uma escola de ensino pré-escolar, no centro da Vila de Americano. O primeiro registro da fazenda data do ano de 1938, e na propriedade é possível encontrar alguns trilhos da estrada de ferro e pedaços de vagões do trem (Brasil, 1997). A Fazenda Nova Sião possui uma área aproximada de 200 hectares e o clima predominante no local é o equatorial quente e úmido, sendo que a vegetação é de floresta primária do tipo floresta tropical úmida. A sua hidrografia é formada por três igarapés, que cortam totalmente o terreno da fazenda, e de quinze nascentes, sendo que algumas delas deságuam no igarapé principal, que vai desembocar no rio Americano e posteriormente no rio Guamá, e as outras nascentes deságuam no antigo açude do terreno (Brasil, 1997).

O empreendimento ecoturístico relacionado com os princípios do ecoturismo (Honey, 1999 apud Kinker, 2002: 22-24) considera:

[...] O atrativo principal é a natureza conservada; produz mínimo impacto no meio ambiente natural e cultural; [...] desperta e sensibiliza o turista e a comunidade local, a fim de formar uma consciência ambientalista; promove benefícios diretos e indiretos para a conservação das áreas visitadas; promove benefícios econômicos e o fortalecimento das comunidades locais [...].

A atividade da Trilha Interpretativa (Trilha do Americano) na Fazenda Nova Sião busca estar de acordo com os princípios do ecoturismo, pois em seu programa interpretativo tenta a prática da conservação da natureza, procurando não causar impactos ao meio ambiente. A trilha passa tanto ao turista como para a comunidade local uma consciência de preservação da natureza e, conseqüentemente, benefícios financeiros à comunidade.
Os autores Mendonça e Neiman (2002: 160) possuem a seguinte visão da natureza:

[...] Quando se entra em uma área natural, quase sempre se passa a sentir algo bom, percebe-se que alguma coisa muda. Quanto mais se aprofunda essa relação, essa intimidade com os elementos naturais, percebe-se que ali há uma grande escola que proporciona uma das raras oportunidades existentes para realmente evoluir. Quem já teve a experiência de, por exemplo, caminhar por uma mesma trilha diversas vezes pode compreender isso: a cada vez, há coisas diferentes que se pode ver ou coisas diferentes em que pensar [...]. Ao se perceber isso, toma-se consciência de si mesmo.

Com isso, é possível afirmar que o desenvolvimento da trilha interpretativa na Fazenda Nova Sião não está apenas na visão empresarial do empreendimento, mas também, e principalmente, na visão de preservação da natureza, pois o objetivo dela se concretiza na busca da conscientização dos turistas e dos habitantes da Vila de Americano.

Ainda segundo Mendonça e Neiman (2002: 168), a cultura é importante para a natureza:

[...] as populações residentes possuem um forte vínculo com a natureza [...] esses povos ainda vivem tendo a natureza como suporte para a manutenção de suas culturas, possivelmente são os únicos a realmente conhecerem as formas de sustentabilidade específicas daqueles ambientes.

A atividade de trilha interpretativa na fazenda não visa buscar um simples contato com a natureza, pois a conservação da natureza dentro da comunidade local torna-se muito importante, por ser a principal responsável pela sua sustentabilidade ambiental, social e cultural.

O potencial desse tipo de projeto ecoturístico já é visto no estado do Amazonas, pois o ecoturismo como meio de sustentação da comunidade do município de Silves está sendo beneficiado desde 1994, com a construção de um hotel por meio da Associação de Silves pela Preservação Ambiental e Cultural (ASPAC) e World Wildlife Fund (WWF), chamado Aldeia dos Lagos, que se tornou auto-sustentável gerando lucro de R $\$ 25 \mathrm{mil} / \mathrm{ano}$, proporcionando assim investimentos no manejo e fiscalização da reserva dos lagos que compõem a região. Esse projeto visou recuperar e conservar os estoques de peixes que estavam ameaçados pela pesca comercial (WWF, 2004). Essa iniciativa somente reforça a idéia de que projetos de ecoturismo que são planejados, executados e monitorados com o apoio de organizações não-governamentais (ONGs), empresários conscientes de seu papel na 
sociedade e o envolvimento da comunidade local podem ser realmente sustentáveis É nesse pensamento que a trilha interpretativa da Fazenda Nova Sião se insere, isto é, planejar, executar e monitorar a atividade ecoturística de trilha interpretativa para beneficiar o meio ambiente, a cultura, os turistas e a comunidade local.

\section{A Trilha Interpretativa da Fazenda Nova Sião}

A Trilha Interpretativa da Fazenda Nova Sião, chamada Trilha do Americano, é guiada e requer a presença de um intérprete ou guia. O seu tipo é natural temática, onde se preparam as paradas com antecedência, dando maior coerência ao passeio, pois as interpretações terão o momento certo para serem realizadas. A trilha tem a função de interpretação ambiental, com formato circular e grau de dificuldade moderado. O tempo de duração da trilha é de três horas, com a distância de 3,5 quilômetros, localizada entre as seguintes coordenadas geográficas: s $01^{\circ} 18^{\prime} 21,4^{\prime \prime}$ e w $48^{\circ} 01^{\prime} 46,4^{\prime \prime}$.

As principais metas a serem alcançadas são: proteger os igarapés e as nascentes e preservar a flora e a fauna. Os principais objetivos da trilha são a conscientização da população local sobre a importância da preservação da flora e da fauna e fornecer à comunidade maior conhecimento sobre o ecoturismo.

A Trilha do Americano possui o tópico "A conservação da natureza" e a mensagem que se deseja passar, ou seja, o tema interpretativo, é: "A necessidade de conservar a natureza na Vila de Americano, para que não ocorra a extinção das espécies de flora e fauna locais".

O autor Ham (1992 apud Carvalho, 2002: 43) afirma que "a apresentação do tema interpretativo deve ser feita de forma interessante e motivadora, envolvendo os participantes, estimulando a observação, a ação e a reflexão". Isso mostra a necessidade de desenvolver pontos principais e disponibilizar informações estruturais organizadas em uma seqüência lógica.

A Trilha de Americano possui seis pontos ou paradas principais, com suas devidas informações, caracterizando seu programa interpretativo, mas isso não impede que ao longo da trilha não sejam feitas outras observações. São eles:

Breve histórico do município de Santa Izabel do Pará e da Vila de Americano (Parada da Antiga Estrada de Ferro Belém-Bragança): A história do desenvolvimento do município de Santa Izabel e da Vila de Americano está principalmente relacionada à antiga Estrada de Ferro Belém-Bragança. (s 01 18' 19,4” e w 48 01' 44,4”).

Açaí: aspectos sociais, econômicos e culturais (Parada do Açaí): As palmeiras, como o açaizeiro (Euterpe oleracea), são encontradas em grande quantidade na Fazenda Nova Sião. Elas têm sido para o homem da região amazônica fonte de matéria-prima, por fornecer: tronco e folhas para a construção de suas casas e utensílios; flores e frutos para sua alimentação, como também o desenvolvimento de produtos como suco, licor, doce, farinha, entre outros. Por exemplo, o açaizeiro é totalmente aproveitado, pois do fruto se tira a polpa, bebida muito consumida no Pará e fora do estado, haja vista que foi comprovado seu valor nutritivo: água, protídios, fibras, lipídios, glicídios, cálcio, fósforo e ferro (Calzavara, 1976).

Economia local versus conservação da natureza (Parada das Nascentes): A não-conservação das nascentes irá prejudicar ou até acabar com os igarapés e rios do município e, além disso, muitas famílias que vivem da caça do tatu-peba (Euphractus sexcinctus), coati (Nasua nasua), bicho-preguiça (Bradypus variegatus), paca (Augouti paca), trinca-ferro (Saltator similis), curió (Oryzoborus angolesis), gato-do-mato (Felis sp), macaco-de-cheiro (Saguinus sciureus), entre outros, praticam a caça predatória, causando também a extinção de várias espécies. Esses fatores trazem conseqüências, como a migração da população local, afetando negativamente a economia. (s $01^{\circ} 18^{\prime} 17.8^{\prime \prime}$ e w $48^{\circ} 01^{\prime} 47.6^{\prime \prime}$ ).

A conservação da natureza versus a ação do homem (Parada do Antigo Açude): O lixo e os esgotos têm sido grandes responsáveis pela poluição da natureza, por exemplo, com a contaminação dos rios, açudes, nascentes, entre outros. Por causa da influência do ser humano, houve a devastação do açude pertencente à fazenda, por causa das águas da chuva e dos esgotos que entram pelos tubos de vazão da BR-316, que estão posicionados para dentro da fazenda, provocando a erosão do terreno e o acúmulo de areia e lixo. (s 01² 18' 18.6” e w 4801’45.2”).

Poluição da natureza versus fauna e flora (Parada da Nascente do Igarapé): Quando se prejudica a nascente de um igarapé, peixes como o acará (Aequidens plagiozonatus) não irão se reproduzir e podem até ser extintos. Outras espécies da fauna identificadas nos igarapés da fazenda foram a rã (Hyla circundata), o sapo (Bufo sp) e o jacaré (Caiman crocodilus), que antes se reproduzia no leito do açude, colocando cerca de 20 a 40 ovos no local. Há também o prejuízo de algumas espécies de plantas e árvores, como o louro preto (Ocotea baturitensis), o louro branco (Ocotea opifera), o louro vermelho (Nectandra rubra), o cupuaçu (Theobromagrandiflorum), o açaí do Pará (Euterpe oleracea), o morototo (Schefflera morototoni), a castanha sapucaia (Lecythis paraensis), entre outras, que são encontradas às margens de rios, igarapés, açudes e nascentes. (s $01^{\circ} 17^{\prime} 45.8^{\prime \prime}$ e w $48^{\circ} 02^{\prime} 00.9^{\prime \prime}$ ).

Preservação do meio ambiente versus benefícios (Parada do Igarapé): Preservar as paisagens, as águas, a vegetação e a vida silvestre pode trazer diversos 
benefícios econômicos, sociais, culturais e ambientais para a comunidade local. Isso pode ocorrer pelo desenvolvimento sustentável do turismo, por trilhas interpretativas bem planejadas, o que gera empregos diretos (participação da comunidade na manutenção da trilha) e indiretos (uso de bens e serviços do município) para a comunidade. (s $01^{\circ} 17^{\prime} 48.5^{\prime \prime}$ e w $48^{\circ} 01^{\prime} 52.2^{\prime \prime}$ ).

Assim como no município de Santa Izabel do Pará, que possui como principais rios Caraparu, Americano, Apeú, Tauá, Ita e Maguari, como também dos igarapés Santa Izabel, Peronga e Orfanato (Ferreira, 1984; PARATUR, 2001), a Fazenda Nova Sião possui uma paisagem única, reunindo também igarapés, fontes de águas naturais (nascentes) e abundância de fauna e flora que a fazem importante para o turismo, particularmente para o desenvolvimento da atividade ecoturística, com o envolvimento da comunidade de Americano. Dessa forma, o ecoturismo com base na comunidade é definido como:

[...] Empreendimentos de ecoturismo de propriedade da comunidade ou geridos por ela. Além disso, o ecoturismo baseado na comunidade implica seu compromisso de cuidar dos recursos naturais, para obter renda por intermédio da operação de um empreendimento de turismo e usar essa renda para melhorar suas condições de vida. Ele envolve conservação, promoção de negócios e desenvolvimento comunitário (Sproule, 1996 apud Fennell, 2002: 207).

A Trilha do Americano pertence a um proprietário que faz parte da população da Vila de Americano, e isso confirma a possibilidade de haver a sustentabilidade dessa comunidade, pois por meio desse empreendimento na Fazenda Nova Sião surgirá, além de oportunidades para a geração de emprego e renda aos habitantes da vila, um compromisso de todos os envolvidos em conservar os recursos naturais do local.

\section{Principais resultados sobre o programa de conservação da Trilha do Americano}

No processo de estudo da Trilha do Americano foram realizadas cem entrevistas envolvendo a comunidade da Vila de Americano e os visitantes de outras localidades que participaram da trilha. Nessa entrevista, procurou-se abordar, principalmente nas perguntas sobre turismo, temas como: "a trilha interpretativa proporciona a preservação do meio ambiente local?" e "como se desenvolveu seu comportamento antes e após participar da trilha?".
Na entrevista, a maioria dos indivíduos é do sexo feminino (65\%), enquanto que os homens corresponderam a 35\% dos entrevistados. A faixa etária dos entrevistados foi em sua maioria de jovens (45\%), entre 16 a 20 anos. Entre a maioria dessas pessoas, $42 \%$ concluíram o ensino médio, $23 \%$ o ensino fundamental e $35 \%$ o ensino superior.

De uma forma geral, tanto os visitantes quanto a comunidade local que participaram da trilha, que em sua maioria foi de estudantes, obtiveram experiências ecoturísticas pelo programa interpretativo dos pontos principais desenvolvidos na Trilha do Americano, causando mudança de comportamento nessas pessoas no que se refere à conservação do meio ambiente. Um exemplo disso foi a manifestação de vários visitantes quanto ao lixo levado por outros grupos. Houve uma coleta voluntária do que ia sendo encontrado durante a trilha. Ou seja, o programa interpretativo desenvolvido durante a Trilha do Americano colaborou de maneira acertada para que a preservação do meio ambiente fosse entendida por todos os visitantes e, conseqüentemente, causasse mudança de comportamento. Outro exemplo favorável causado pelo programa interpretativo da trilha foi o aumento de conhecimento da população local em relação ao ecoturismo, pois todos os visitantes da trilha, além de acompanharem os principais pontos interpretativos do programa, também receberam material informativo (folder) com informações sobre ecoturismo e a comunidade local.

Fennell (2002: 204), considera que "[...] o turismo é visto cada vez mais como a ferramenta-chave no desenvolvimento comunitário [...] sua contribuição às economias estagnadas, diversificação de setores e sua capacidade de unir os membros da comunidade". Isso confirma e reforça a idéia de quanto um produto ecoturístico, como a Trilha do Americano, é importante para uma comunidade e seus visitantes, sendo que esse mesmo produto deve ter planejamento adequado, estratégias a longo prazo, e o mais importante, priorizar a conservação do meio ambiente, pois sem esses recursos o empreendimento turístico não terá êxito. Sproule (1996 apud Fennell, 2002: 207) afirma: “[...] o ecoturismo baseado na comunidade implica seu compromisso de cuidar dos recursos naturais, para obter renda por intermédio [...] empreendimento de turismo e usar essa renda para melhorar suas condições de vida [...]". Isso implica a necessidade de se ter conhecimento sobre turismo, pois só assim a comunidade poderá cuidar e, conseqüentemente, se manter por meio de empreendimentos turísticos. Ou seja, a educação tem papel fundamental nesse processo fortalecedor do ecoturismo, fazendo da Trilha do Americano um meio de difusão de informações e de sustento turístico para a comunidade, pelo seu programa interpretativo.

Algumas sugestões feitas pelos visitantes da trilha afirmavam que deveriam ocorrer estratégias voltadas para o turismo, no caso específico da Trilha do America- 
no, que devem centralizar a articulação entre a comunidade e os empreendedores junto aos representantes públicos locais para inserir os projetos ecoturísticos, como a própria trilha, com convênios municipais, estaduais e federais fomentados, por exemplo, pelo PNT - Plano Nacional de Turismo. Mas, para isso acontecer, será preciso que o turismo seja "[...] viável como uma estratégia econômica [...] os problemas sociais e ecológicos precisam ser tratados e a base de recursos precisa ser protegida. A comunidade [...] é a base do recurso econômico, social, cultural e infra-estrutural para [...] o turismo [...]" (Fennell, 2002: 205). Isto é, para se ter melhoria na qualidade de vida da população, é necessário que o planejamento seja centrado na própria comunidade, alcançando-se com isso o desenvolvimento econômico, social e a preservação da natureza.

\section{Considerações finais}

Este artigo apresentou a Trilha do Americano, mostrando a relação de três agentes, que são a comunidade local, o visitante e o ecoturismo. Entre os agentes surge uma visão do produto ecoturístico, mostrando ser possível que o ecoturismo possa se tornar a "chave" dessa relação, pois por meio dos princípios como a conscientização ambiental, a participação direta da comunidade e a preservação de recursos naturais, os agentes poderão interagir na sociedade atual de uma forma equilibrada, conservando o meio ambiente.

A trilha interpretativa é fator importante para o ecoturismo, pois, além de identificar dados e fatos importantes para a atividade turística, busca mudar a postura do visitante e da comunidade local perante a natureza, dando-lhes uma consciência ecológica quanto à preservação do meio ambiente.

Com base na pesquisa desenvolvida, conclui-se que o estudo da Trilha do Americano introduziu a temática do ecoturismo, criando uma estratégia de conservação do meio ambiente por meio do programa dos pontos interpretativos da trilha, que sensibilizou a população local e os visitantes de outras localidades quanto à conscientização ambiental, à importância da preservação da flora e fauna da Vila de Americano e à atividade ecoturística, que pode trazer benefícios econômicos, sociais, culturais e ambientais.

\section{Referências bibliográficas}

ANDRADE, Waldir Joel de. Manejo de trilhas. [S.d.] Disponível em: <http://geocities.yahoo.com.br/grupochaski/downloads/trilha.doc. . Acesso em: 5 nov. 2003.

BRASIL. 1997. Único ofício de serviço notorial e de registro do Distrito, Município e Comarca de Santa Izabel do Pará do Estado do Pará. Escritura pública de compra e venda de um terreno rural situado no município de Santa Izabel do Pará. Santa Izabel do Pará.
CALZAVARA, Batista Benito G. 1976. As possibilidades do açaizeiro no estuário amazônico. SIMPÓSIO INTERNACIONAL SOBRE PLANTAS DE INTERÉS ECONOMICO DE LA FLORA AMAZONICA. IICA, PROGRAMA PARA EL DESARROLLO DEL TRÓPICO AMERICANO, Costa Rica, Unidad de Documentación.

CARVALHO, Francisco Neves. 2002. Projeto doces matas: manual de introdução à interpretação ambiental. Belo Horizonte. Disponível em: <http://www.ief.mg.gov.br/docesmatas/publicacoes.htm>. Acesso em: 1 jan. 2004.

DENCKER, Ada de Freitas Maneti. 1998. Métodos e técnicas de pesquisa em turismo. São Paulo: Futura. FENNELL, David A. 2002. Ecoturismo: uma introdução. São Paulo: Contexto.

FERREIRA, Nestor. 1984. História do município de Santa Izabel do Pará. Belém: Falangola.

KINKER, Sônia. 2002. Ecoturismo e conservação da natureza em parques nacionais. Campinas, SP: Papirus. LEMOS, Amália Inês. 1996. Turismo: impactos socioambientais. São Paulo: Hucitec.

MENDONÇA, Rita \& NEIMAN, Zysman. 2002. Ecoturismo: discurso, desejo e realidade. In: NEIMAN, Zysman (Org.). Meio ambiente, educação e ecoturismo. Barueri, SP: Manole.

MURTA, Stela Maris \& GOODEY, Brian. 2002. Interpretação do patrimônio para visitantes: um quadro conceitual. In: MURTA, Stela Maris \& ALBANO, Celina (Org.). Interpretar o patrimônio: um exercício do olhar. Belo Horizonte: UfMG. p. 13-46.

PAGANI, Maria I. et al. 1996. As trilhas interpretativas da natureza e o ecoturismo. In: LEMOS, Amália Inês G. Impactos socioambientais. São Paulo: Hucitec.

PARATUR. 2001. Inventário turístico do município de Santa Izabel do Pará. Belém.

SERREL, Beverly. 1996. Exhibit labels: an interpretive approach. Walnut Creek: Altamira Press.

SOUZA, André Luiz Lopes de. 1994. Meio ambiente e desenvolvimento sustentável: uma reflexão crítica. Belém: UfPA/NAEA (Paper do NAEA, 45).

WEARING, Stephen \& NEIL, John. 2001. Ecoturismo: impactos, potencialidades e possibilidades. Barueri, SP: Manole.

WORLD WILDLIFE FUND. 1994. Ecoturismo integrado ao manejo de várzea em Silves. Silves. Disponível em: $<$ http://www.wwF.org.br/projetos/projeto.asp?lista=bioma\& item=1\&item=53>. Acesso em: 20 jan. 2004.

Recebido em: 06/05/2005.

Aprovado em: 24/03/2006. 